\title{
Effects of Ultra-Low-Dose Aspirin in Thrombosis and Haemorrhage
}

\author{
Francisco Xavier Eizayaga ${ }^{1}$ Philippe Belon ${ }^{2}$ Vanessa Desplat ${ }^{3}$ Omar Aguejouf ${ }^{3}$ \\ Christian Doutremepuich ${ }^{3}$
}

${ }^{1}$ Departamento de Homeopatía, Universidad Maimónides, Buenos Aires, Argentina

${ }^{2}$ Centre de Recherche et de Documentation Thérapeutique, Lyon, France

${ }^{3}$ Laboratoire d'Hématologie, UFR des Sciences Pharmaceutiques, Université de Bordeaux, Bordeaux, France

Address for correspondence Francisco Xavier Eizayaga, MD, PhD, Departamento de Homeopatia, Escuela de Medicina, Universidad Maimonides, Buenos Aires, Argentina

(e-mail: homeopatia@maimonides.edu).

Homeopathy 2019;108:158-168.

\begin{abstract}
Background Aspirin is the oldest and possibly the most widely used pharmacologically active substance still used in allopathic medicine. Its effect on fever and inflammation has paved the way to its anti-thrombotic effect. Dilutions of aspirin have been tested for many years in the University of Bordeaux, in humans as well as in animal models.

Methods This article is a review of the totality of articles published by the Laboratory of Hematology of the Faculty of Pharmacy of the University of Bordeaux, reporting different doses and dilutions of aspirin, different kinds of inhibitors, transgenic mice and animal models of disease such as portal hypertension and cirrhosis.

Results Homeopathic dilutions of aspirin, notably $15 \mathrm{cH}$, have shown a pro-thrombotic effect in humans and in in-vivo animal studies. Longitudinal studies in rats have also shown an initial anti-thrombotic effect followed by a pro-thrombotic effect of aspirin several days after a single high-dose administration. This pro-thrombotic effect seems to act by inhibiting the cyclooxygenase (COX)-2 pathway in studies performed with COX selective inhibitors and in knock-out mice without COX-1 or COX-2. This effect

\section{Keywords}

- aspirin $15 \mathrm{cH}$

- thrombosis

- portal hypertension

- homeopathy

- COX inhibition

- aspirin withdrawal may explain the thrombo-embolic complications described after aspirin withdrawal for the purposes of surgery or after non-compliance with anti-platelet therapy, and it may be beneficial in normalising primary haemostasis and decreasing haemorrhage in animal models of portal hypertension and cirrhosis.

Conclusions Aspirin $15 \mathrm{cH}$ acts through the inhibition of the COX-2 pathway producing a clear pro-thrombotic effect. Further studies should clarify if the pro-thrombotic effect of aspirin withdrawal and the effect of aspirin $15 \mathrm{cH}$ are related, as secondary effects of the same drug. Clarifying this last outcome may be of great significance to public health.
\end{abstract}

\section{Introduction}

Aspirin is the oldest substance used in allopathic medicine and probably the most used up to now. The history of aspirin began many thousands of years ago with the decoction or preparations of plants, such as willow bark that contain salicylic acid. The success of those preparations prompted the house of Frederick Bayer to search for a derivative of comparable or better efficacy to salicylic acid. This task was given to Felix Hoffmann, who found the way to acetylate the hydroxyl group on the benzene ring of salicylic acid to form acetylsalicylic acid in 1895 . Little was known about the received

August 20, 2018

accepted after revision

October 31, 2018

published online

April 20, 2019
Copyright $\odot 2019$ The Faculty of Homeopathy
DOI https://doi.org/ 10.1055/s-0038-1677495. ISSN $1475-4916$. 
mechanism of the effect of aspirin before the work of Sir John Vane in the early 1970s. ${ }^{1}$ For the discovery of the role of aspirin blocking the production of prostaglandins by inhibiting an enzyme widely known today as cyclooxygenase (COX), he was awarded the Nobel Prize in 1971.

Aspirin is almost no longer used as a non-steroidal antiinflammatory drug because of the existence of more powerful drugs. The use of aspirin for treating fever in children has almost disappeared because of Reye's syndrome, a kind of liver failure with hepatic encephalopathy. The main indication for aspirin is secondary prevention of cardiovascular ischaemic problems. Aspirin, when ingested, is rapidly absorbed and generates an inhibition of COX-1, acetylating serine 530 . The inhibition of COX-1 produced by aspirin is not reversible. In the platelet this effect almost stops the synthesis of thromboxane $\mathrm{A}_{2}\left(\mathrm{TXA}_{2}\right)$ and in the endothelial cell it decreases the synthesis of prostacyclin $\left(\mathrm{PGI}_{2}\right)$. The endothelial cell, which has COX-2 and a nucleus that allows new synthesis of COX-1, finds the way to generate new $\mathrm{PGI}_{2}$. Because of the definitive inhibition of COX-1 and the absence of nucleus, the decrease in $\mathrm{TXA}_{2}$ production in the platelet remains for its life. The result of the imbalance between a normal $\mathrm{PGI}_{2}$ secreted by endothelial cells and a decreased $\mathrm{TXA}_{2}$ in platelets is a clear anti-thrombotic effect.

In the mid-1980s, the Laboratory of Haematology of the Faculty of Pharmacy in the University of Bordeaux started a study on the effect of ultra-low doses of aspirin (ASA). These studies have shown a paradoxical, reproducible, pro-thrombotic effect in human and in animal studies. For more than 20 years, these studies were conducted in the search for an explanation of this effect and the mechanisms involved. The present paper is a review of articles published by this Laboratory of Hematology, reporting different kinds of inhibitors, transgenic mice and animal models of diseases, such as portal hypertension and cirrhosis. Its writing was the direct result of personal encouragement to do so by Dr Peter Fisher, former Editor-in-Chief of this journal.

\section{Effect of Aspirin on Platelets}

The initial studies in ultra-low doses of ASA were started around 1985 . The protocol used at that time was performed in 20 healthy volunteers with an average age of 26 years. The medicine used was a single dose of ASA $5 \mathrm{cH}$, in liquid form, with a volume of $2 \mathrm{~mL}$. The bleeding time was significantly shortened and thrombin time was prolonged. Platelet count and platelet aggregation induced by collagen showed no variations. An in-vitro study was designed, incubating blood for 10 minutes at $37^{\circ} \mathrm{C}$ in three groups: (1) control group with saline solution; (2) saline solution with a fragment of human saphenous vein; (3) same as group 2 plus ASA $5 \mathrm{cH}, 1 \% \mathrm{v} / \mathrm{v}$. These solutions were put together with platelet-rich plasma from healthy donors and then standard aggregometry was performed. As a result, group 2 showed a decrease in the parameters of platelet aggregation, and an increase in the same parameters in group 3 which was treated with ASA 5 $\mathrm{cH}$. Moreover, this effect of aspirin was not modified by papain, a proteolytic enzyme. ${ }^{2-7}$

\section{Effect of Aspirin on Endothelial Cells}

As the previous studies suggested that both platelets and endothelial cells were possibly involved in this effect, a model that allowed the in-vivo observation of the interaction of platelets and endothelial cells was needed. A method of laser-induced thrombosis was used. After placing the intestinal loop of a Wistar rat on an inverted microscope table, vascular lesions were induced with an Argon laser. This experimental model was complemented by measuring induced haemorrhagic time (IHT) in rat tail as a simple indicator of primary haemostasis.

A schematic view of the apparatus used has been previously described. ${ }^{8}$ Arterioles between 15 and $25 \mu \mathrm{m}$ diameter were used. Two parameters were assessed during each procedure: the number of platelet emboli removed from the thrombus by blood flow after an injury produced by the laser shot; the duration of embolisation, defined as the time between the first and the last emboli occurring after thrombus formation, expressed in minutes. This study had the particular benefit of allowing observation of the in-vivo generation of emboli with the participation of endothelial cells and platelets.

An experimental model of IHT was established 10 minutes before thrombosis induction by laser. Under general anaesthesia of the animal, the tail of the rat was immersed for 5 minutes at $37^{\circ} \mathrm{C}$ and sectioned $6 \mathrm{~mm}$ from the extremity. IHT corresponded to the time between tail section and the end of bleeding and was expressed in seconds. The early studies with the laser-induced thrombosis method were performed with a fixed dose of $0.2 \mathrm{~mL}$ ASA $15 \mathrm{cH}$ (which was changed in subsequent studies to $1 \mathrm{~mL} / \mathrm{kg}$ body weight [b.w.]) and with vessels of $50 \mu \mathrm{m}$ diameter (afterwards changed to $20 \mu \mathrm{m}$ diameter). The laser-induced endothelial lesion was performed 1 hour after ASA injection. Observations showed a decrease in the number of laser injuries required to induce thrombus formation, an increase in number of emboli removed by the bloodstream, and an increase in the duration of embolisation. The impact on thrombus formation indicated a strong pro-thrombotic effect of ultra-low doses of ASA. $^{8}$

\section{Elapsed Time and the Effect of a Single High Dose of Aspirin}

Aspirin has a primary anti-thrombotic effect but also seems to have a strong pro-thrombotic effect when used in the 15th centesimal dilution. The question raised afterwards was if a high dose of aspirin would produce the same effect once the primary anti-thrombotic effect decreased (secondary effect).

This study was conducted with nine groups of rats. Group 1 was injected with placebo and the remaining groups were injected with a single high dose of ASA $100 \mathrm{mg} / \mathrm{kg}$ and studied with the laser-induced thrombosis method at 2, 4, $6,8,10,12,14$ and 16 days after the injection. On day 2 , the number of emboli and the duration of embolisation decreased significantly. There was also a significant increase in the number of emboli on day 8 and duration of 
embolisation on days 8 and 10 after injecting a high dose of ASA, similar to the pro-thrombotic effect observed 1 hour after ASA $15 \mathrm{cH} .{ }^{9}$ Further studies have shown that when ASA $15 \mathrm{cH}$ was injected shortly after a high dose of ASA $100 \mathrm{mg} / \mathrm{kg}$ b.w., the anti-thrombotic effect was not present and the bleeding time was shortened when compared to the control group, suggesting that ASA $15 \mathrm{cH}$ may have a neutralising effect over the higher, anti-thrombotic doses (-Figs. 1 and 2). ${ }^{10,11}$

\section{Extended Dose Response of Aspirin}

Aspirin was also studied from a pharmacological point of view with an extended dose-response curve for IHT and laserinduced thrombosis in the rat. The doses studied ranged from salicylate $100 \mathrm{mg} / \mathrm{kg}$ and aspirin in doses of $100 \mathrm{mg} / \mathrm{kg}$, $1 \mathrm{mg} / \mathrm{kg}, 1 \mathrm{cH}, 2 \mathrm{cH}, 3 \mathrm{cH}, 4 \mathrm{cH}, 5 \mathrm{cH}, 9 \mathrm{cH}, 15 \mathrm{cH}$ and $30 \mathrm{cH}$. The results showed an anti-thrombotic and haemorrhagic effect of aspirin $100 \mathrm{mg} / \mathrm{kg}$ and $1 \mathrm{mg} / \mathrm{kg}$ and a clear pro-thrombotic effect of potencies $9 \mathrm{cH}, 15 \mathrm{cH}$ and $30 \mathrm{cH}^{12}$

\section{Effect of Aspirin after Non-selective and Selective Inhibition of Cyclooxygenase}

Additional studies were then performed to clarify the mechanism underlying this paradoxical effect. The pathway of COX was studied after demonstrating that the effect of ASA $15 \mathrm{cH}$ was modified with pre-treatment of indomethacin (a typical non-selective COX inhibitor) but not with nitro-Larginine methyl ester (NAME) (inhibitor of the pathway of nitric oxide [NO]). The possibility of an effect on the pathway of COX led the group to a study with COX-specific inhibitors. For inhibition of COX-1, SC-560 was used, and NS-398 for the inhibition of COX-2. Both were used at a dose of $10 \mathrm{mg} / \mathrm{kg}$ b.w. and administered by gavage in a suspension of carboxymethyl cellulose (CMC) at $0.5 \%$ at a final volume of $1 \mathrm{~mL} / \mathrm{kg}$. The inhibitors were administered 1 hour before aspirin injection and the laser procedure was conducted 60 minutes after ASA injection, immediately after IHT was performed. The results were interesting. Induced haemorrhagic time was slightly prolonged after COX-1 inhibition with SC 560 . ASA $15 \mathrm{cH}$ shortened IHT in rats with COX-1 inhibition, but the effect was not observed in rats with COX-2 inhibition. In the laser-induced thrombosis procedure, ASA $15 \mathrm{cH}$ increased the number of emboli and duration of embolisation in normal rats and in rats with COX-1 inhibition, but no effect was observed after COX-2 selective inhibition ( - Figs. 3 and 4). This effect of ASA $15 \mathrm{cH}$ was observed despite the fact that COX-1 inhibition with SC 560 had an opposite effect of decreasing the number of emboli and duration of embolisation. These results were partially presented in the scientific sessions of the American Heart Association (AHA) in Chicago, United States, ${ }^{13}$ and then fully published in the journal Pathophysiology of Haemostasis and Thrombosis. ${ }^{14}$

Two confirmatory studies of these results were carried out. The first one included a huge study of a crossed dose-response curve with ASA, a COX-1 inhibitor and a COX-2 inhibitor, and only with the laser-induced thrombosis method. Five doses of each COX selective inhibitor $(0,2.5,5,7.5$ and $10 \mathrm{mg} / \mathrm{kg}$ b.w.) were matched with five different doses of ASA(100 mg/kg b.w.,

\section{Number of emboli}

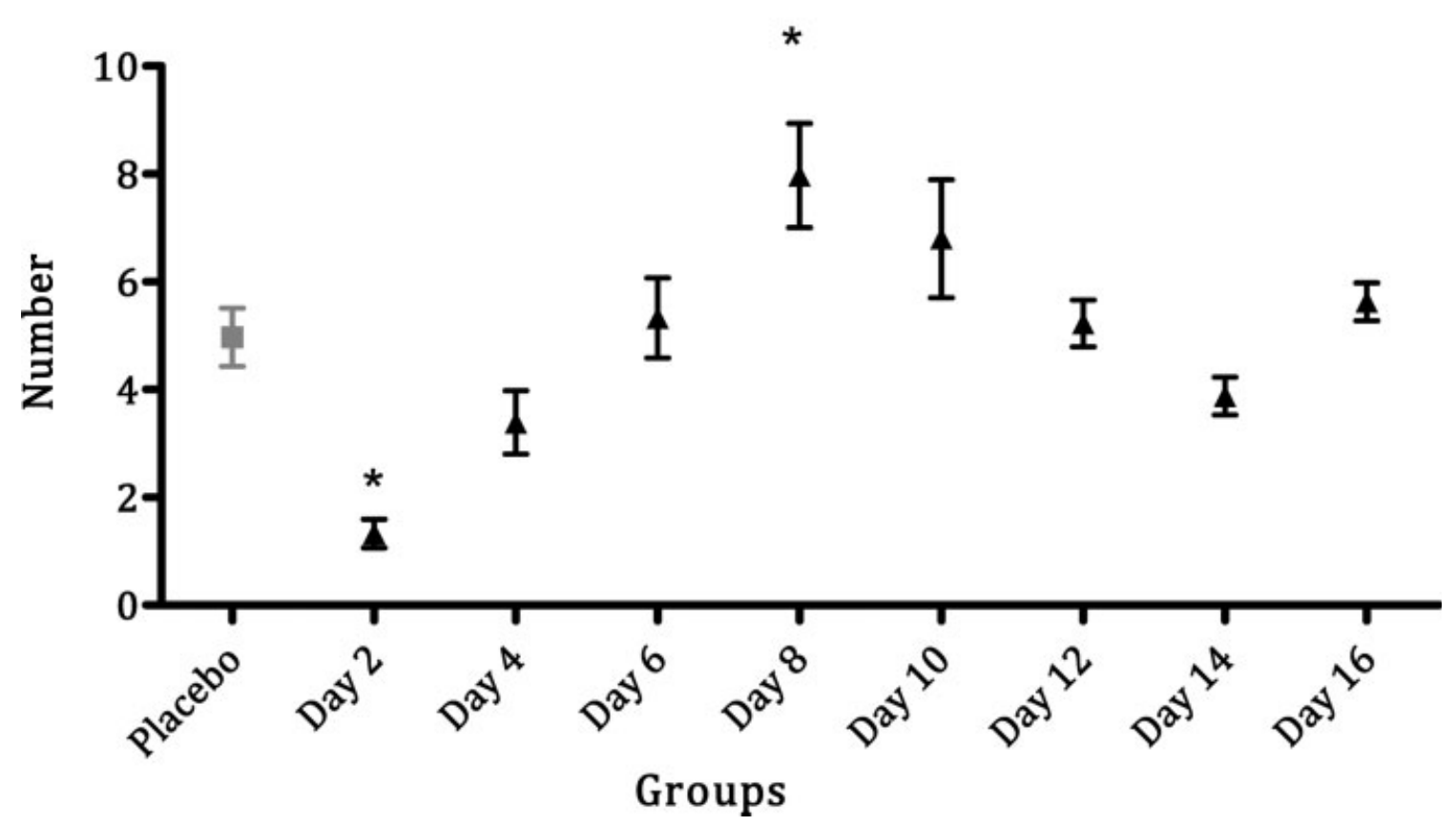

Fig. 1 Thrombo-embolic complications several days after a single-dose administration of aspirin $100 \mathrm{mg} / \mathrm{kg}$ in rats. Laser-induced thrombosis. Study of emboli expressed in numbers. First-column placebo; subsequent columns aspirin $100 \mathrm{mg} / \mathrm{kg}$ one single dose at T0 and studied 2 to 16 days after injection. Statistical analysis: analysis of variance, with Dunnett's post-test, ${ }^{*} p<0.05$ versus placebo. Mean \pm standard error of mean. Graph created with data extracted from original publication. ${ }^{9}$ 


\section{Duration of embolisation}

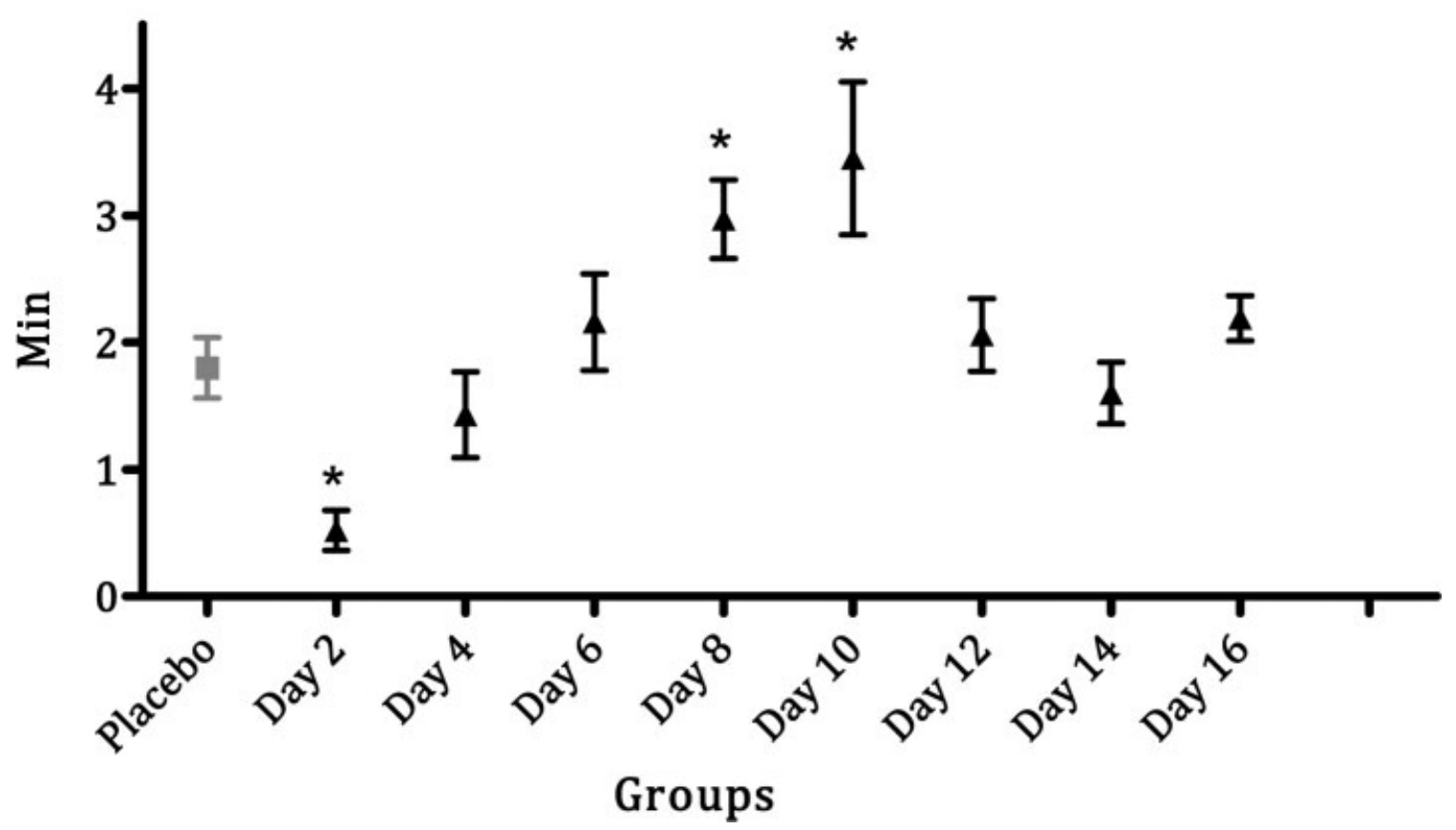

Fig. 2 Thrombo-embolic complications several days after a single-dose administration of aspirin $100 \mathrm{mg} / \mathrm{kg}$ in rats. Laser-induced thrombosis. Study of duration of embolisation, expressed in minutes. First-column placebo; subsequent columns aspirin $100 \mathrm{mg} / \mathrm{kg}$ one single dose at T0 and studied 2 to 16 days after injection. Statistical analysis: analysis of variance, with Dunnett's post-test, ${ }^{*} p<0.05$ versus placebo. Mean \pm standard error of mean. Graph created with data extracted from original publication. ${ }^{9}$

$1 \mathrm{mg} / \mathrm{kg}$ b.w., $5 \mathrm{cH}, 9 \mathrm{cH}$ and $15 \mathrm{cH}$ ). Each dose of ASA had its own matched group of placebo controls. This allowed the preparation of each placebo with the same procedure as the corresponding ASA group. As some previous articles have been criticised for using distilled water for placebo, in this study each ASA placebo had its own preparation following the procedure of the active group, the only difference being that the ASA was not added. In addition to these groups, separate groups were formed with simultaneous inhibition of COX-1 and COX-2 at $10 \mathrm{mg} / \mathrm{kg}$ b.w., with ASA in different doses

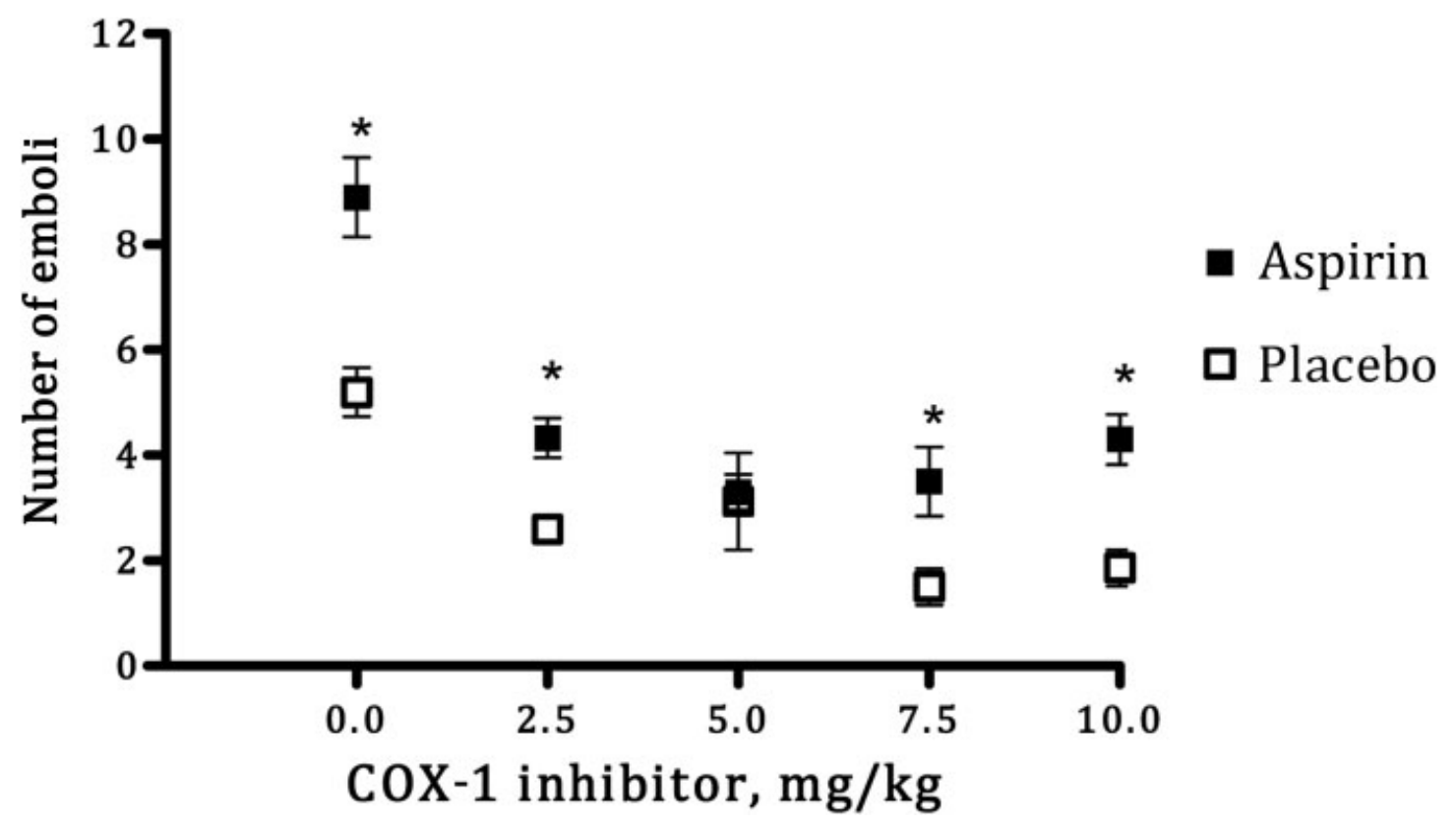

Fig. 3 Effect of aspirin $15 \mathrm{cH}$ with increasing doses of SC-560, specific inhibitor of cyclooxygenase-1. Laser-induced thrombosis. Study of emboli expressed in numbers. Student's t-test: ${ }^{*} p<0.05$, aspirin $15 \mathrm{cH}$ versus placebo. Mean \pm standard error of mean. Unpublished figure with data extracted from original publication. ${ }^{15}$ 


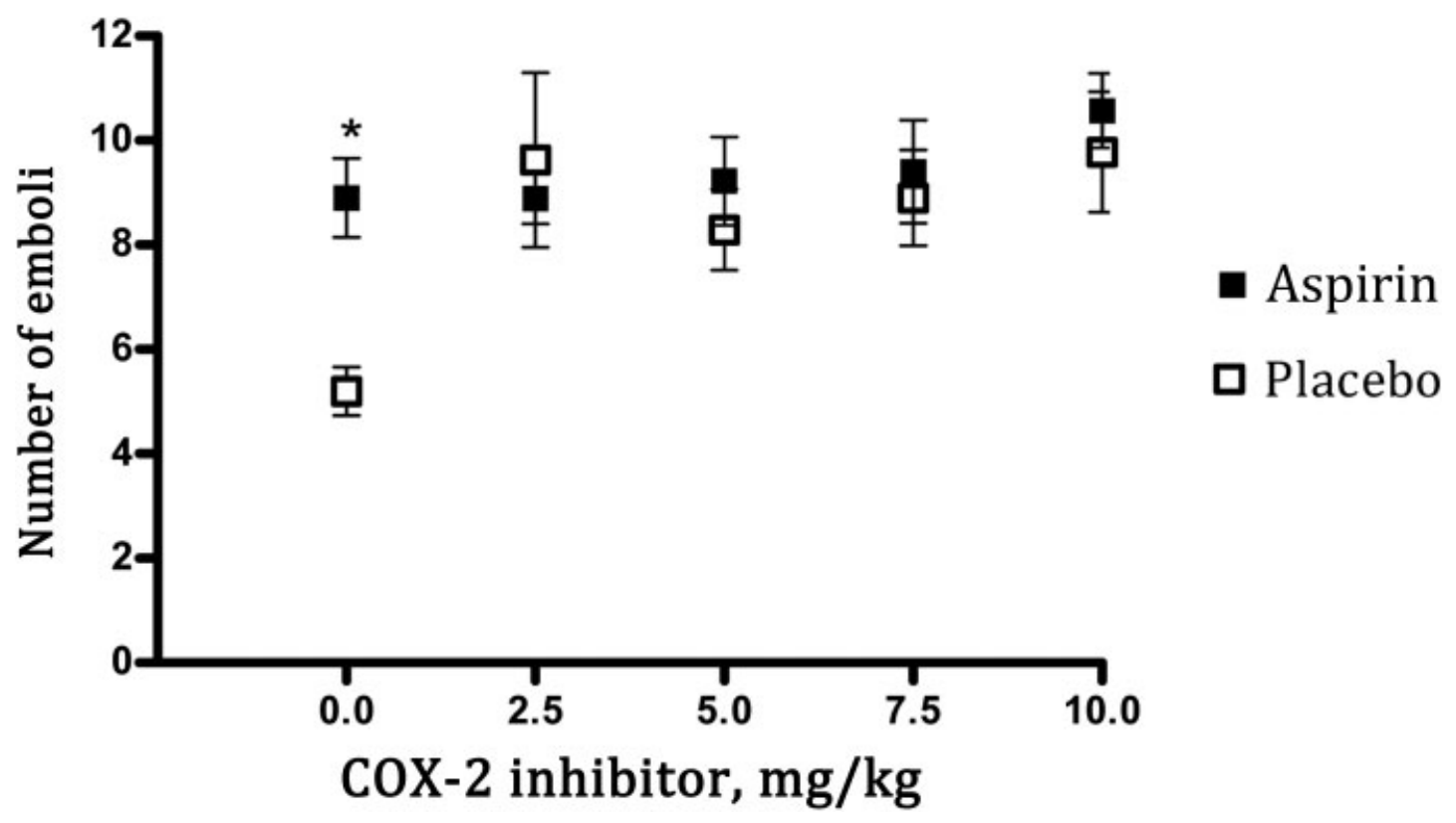

Fig. 4 Effect of aspirin $15 \mathrm{cH}$ with increasing doses of NS-398, specific inhibitor of cyclooxygenase-2. Laser-induced thrombosis. Study of emboli expressed in numbers. Student's t-test: ${ }^{*} p<0.05$, aspirin $15 \mathrm{cH}$ versus placebo. Mean \pm standard error of mean. Unpublished figure with data extracted from original publication. ${ }^{15}$

(100 mg/kg b.w, $1 \mathrm{mg} / \mathrm{kg}$ b.w., $5 \mathrm{cH}, 9 \mathrm{cH}$ and $15 \mathrm{cH}) .^{15}$ The realisation of this extended study took more than 1 year for the laser investigation plus statistical analysis. As a result of this crossed dose-response study, the higher doses of ASA $(100 \mathrm{mg} / \mathrm{kg}$ and $1 \mathrm{mg} / \mathrm{kg}$ ) decreased thrombosis in a significant way, while the lower ones $(9 \mathrm{cH}$ and $15 \mathrm{cH})$ increased thrombosis when compared to control. COX-1 inhibition decreased thrombosis in a significant manner. This decrease in thrombosis blunted, in the higher doses of COX-1 inhibition, the effect of aspirin at the doses of 100 and $1 \mathrm{mg} / \mathrm{kg}$ b.w. However, the anti-thrombotic effect of COX-1 inhibition did not stop the pro-thrombotic effect of ASA 5, 9 and $15 \mathrm{cH}$. The groups that underwent COX-2 inhibition showed an apparent global increase in thrombosis. In these groups, ASA 100 and $1 \mathrm{mg} / \mathrm{kg}$ b.w. had an effect of decreasing thrombosis but the effects of ASA 5, 9 or $15 \mathrm{cH}$ were not observed. These results were again interpreted as a possible effect of ASA $15 \mathrm{cH}$ inhibiting the pathway of COX-2 and being independent of COX-1 inhibition. In the groups with simultaneous inhibition of COX-1 and COX-2, there was an anti-thrombotic effect in general, with some mild pro-thrombotic effects of ASA 9 and $15 \mathrm{cH}$, the latter being the more effective.

\section{Effect of Aspirin on Knockout Mice without Cyclooxygenase-1 or Cyclooxygenase-2}

The second study was done in homozygous knock-out mice COX-1(-l-) and COX-2(-l-). These mice, lacking the specific COX, were used to confirm the results observed with the inhibitors. The doses of ASA and placebos were similar to the previous study (100 mg/ kg b.w., $1 \mathrm{mg} / \mathrm{kg}$ b.w., $5 \mathrm{cH}, 9 \mathrm{cH}$ and $15 \mathrm{cH}$ ). In this study, IHT was performed along with the laser-induced thrombosis method. IHT in COX-1(-/-) mice reported no effect with the higher doses of ASA but a sig- nificant shortening only with ASA $15 \mathrm{cH}$. No clear effects with any dose were obtained with this method in COX-2(-/-) mice. In the laser-induced thrombosis method, with $\operatorname{COX}-1(-/-)$ mice there was a clear increase in the number of emboli and duration of embolisation with ASA $15 \mathrm{cH}$. ASA $100 \mathrm{mg} / \mathrm{kg}$ decreased mildly but significantly the number of emboli in these knock-out mice, being an effect that needs further study. However, the only and pronounced effect on COX-2(-/-) mice was a decrease in the number of emboli and duration of embolisation with ASA $100 \mathrm{mg} / \mathrm{kg}$. These two studies confirmed that the effect of ASA $15 \mathrm{cH}$ was not influenced by the inhibition or absence of $\mathrm{COX}-1$, but was inactivated by previous COX-2 inhibition or by the absence of COX-2 ( - Figs. 5 and $\mathbf{6}$ ). Part of this information was presented in the scientific sessions of the AHA in Orlando, Florida, United States in 2009 and finally fully published. ${ }^{16,17}$

\section{Effect of Aspirin 15 cH on Rats with Portal Hypertension}

Portal hypertension can be a deadly complication of liver cirrhosis. Haemorrhage is caused by several factors. Haemodynamic problems, largely due to increased portal venous inflow resistance, produce increased vascular mesenteric production of $\mathrm{PGI}_{2}$ and NO. The imbalance of increased vasodilator substances and low vascular response to vasoconstrictors increases the blood mesenteric inflow and hence porto-systemic shunts develop. Dilatations of the submucous veins in the lower oesophagus and in the upper part of the stomach increase the possibility of bleeding. Adding to these mechanical factors is the lower production of coagulation factors by reduced liver function and an altered primary haemostasis due to increased $\mathrm{PGI}_{2}$ and $\mathrm{NO}$ which, besides their vasodilator effect, decrease platelet-endothelium interaction. Because of 


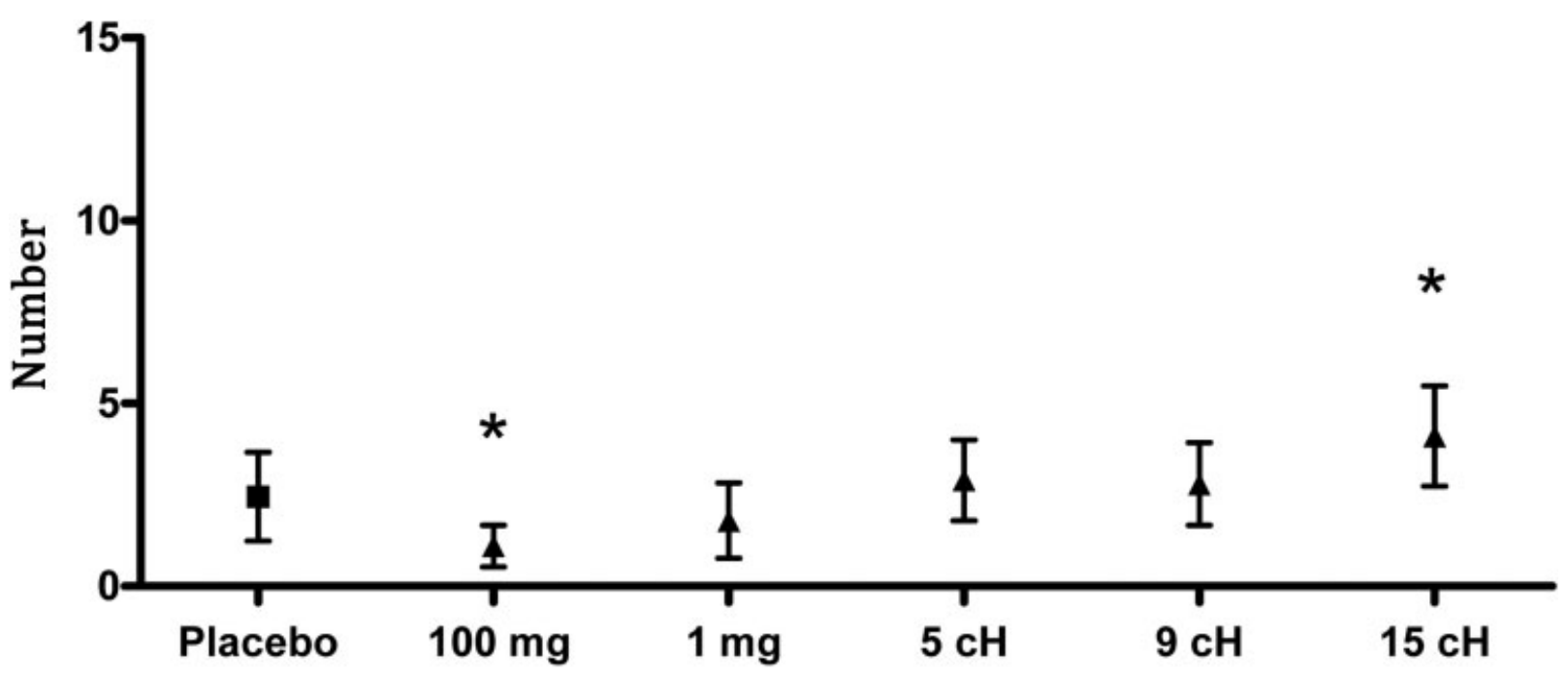

Fig. 5 Laser-induced thrombosis; emboli expressed in numbers. Effects of aspirin at $100 \mathrm{or} 1 \mathrm{mg} / \mathrm{kg}$ and $5 \mathrm{cH}, 9 \mathrm{cH}$ or $15 \mathrm{cH}$ in $\mathrm{COX}-1$ (-/-) mice. Analysis of variance with Dunnett's post-test: ${ }^{*} p<0.01$ versus placebo. Mean \pm standard error of mean. Significantly modified from data in original publication. $^{17}$

its effect of decreasing haemorrhage and increasing thrombosis, ASA seemed a possible candidate for decreasing haemorrhage in portal hypertension.

The first study was done with four groups of Wistar rats. Two were treated with ASA $15 \mathrm{cH}$ and two with placebo. One of these two groups in each treatment sub-set was submitted to calibrated portal vein stenosis, a common model for reproducing the haemodynamic changes observed in portal hypertension. The result of the stenosis is an increase in portal pressure of approximately $50 \%$ between days 1 and 20 . The other two groups were submitted to the same procedure without adding the ligature and were used as control (sham operated).

The production of portal hypertension showed a prolonged IHT and, in the laser-induced thrombosis method, a decrease in the number of emboli and in the duration of embolisation. In the group with portal hypertension and ASA $15 \mathrm{cH}$, IHT, the number of emboli and duration of embolisation were normalised. The results were confirmed in a second study, which also showed the apparently beneficial effects of ASA $15 \mathrm{cH}$ in rats with portal hypertension over haemorrhage and thrombosis. ${ }^{18}$

$\mathrm{PGI}_{2}$ and $\mathrm{NO}$ are important final endothelial vasodilators in the mesenteric vasculature of this model of portal hypertension and both have an important effect inhibiting platelet-endothelial cell adhesion. A study was therefore designed, with 12 groups, using indomethacin (a COX nonselective inhibitor, hence inhibitor of $\mathrm{PGI}_{2}$ production) and NAME (an inhibitor of NO production). The first four groups were the same as for the above explained study; another four groups, similar to these, were injected with indomethacin; and the last four groups were injected with NAME. The most

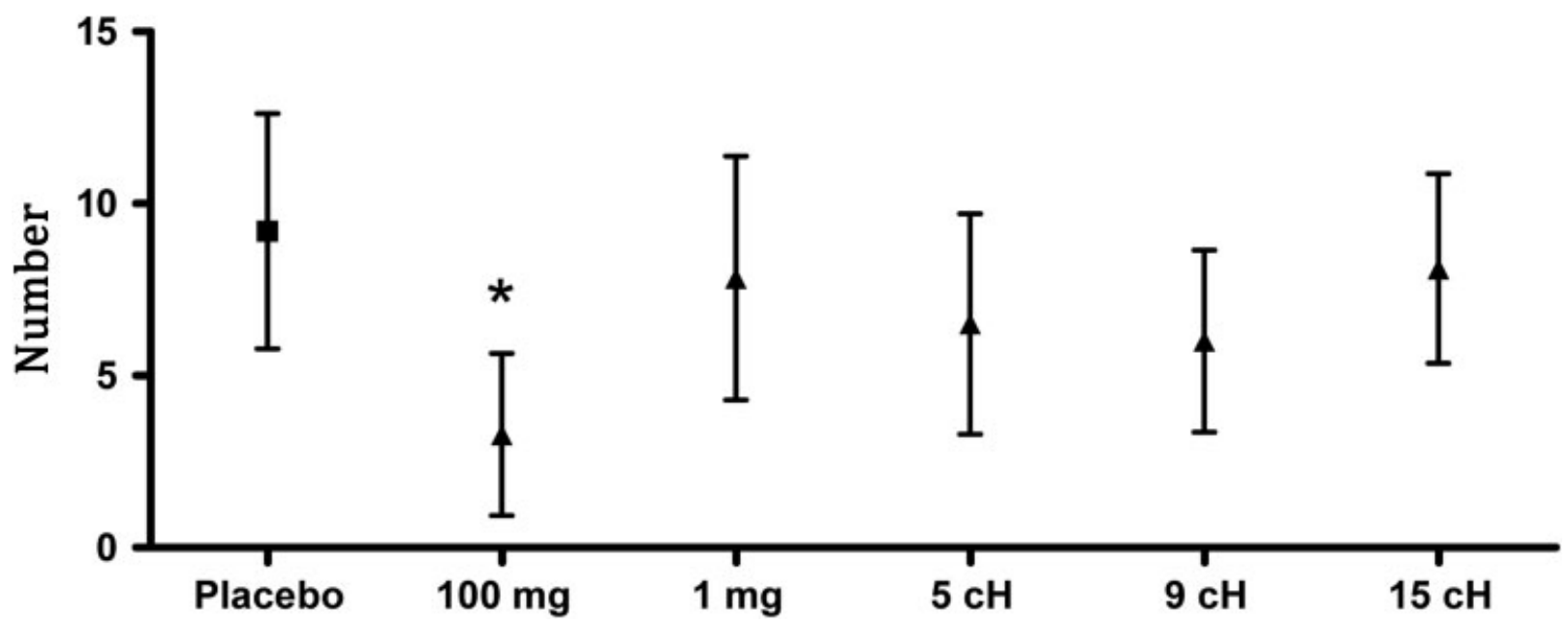

Fig. 6 Laser-induced thrombosis; emboli expressed in numbers. Effects of aspirin at 100 or $1 \mathrm{mg} / \mathrm{kg}$ and $5 \mathrm{cH}, 9 \mathrm{cH}$, or $15 \mathrm{cH}$ in cyclooxygenase$2-/-$ mice. Analysis of variance with Dunnett's post-test: ${ }^{*} p<0.01$ versus placebo. Mean \pm standard error of mean. Significantly modified from data in original publication. ${ }^{17}$ 
striking change observed in this study was that, despite the fact that indomethacin has an anti-thrombotic effect, it seemed to enhance the pro-thrombotic effect of ASA $15 \mathrm{cH}^{19}$

\section{Effect of Aspirin $15 \mathrm{cH}$ on Rats with Portal Hypertension and Non-selective or Selective Inhibition of Cyclooxygenase}

Indomethacin is a non-selective COX inhibitor, with a slightly more powerful effect inhibiting COX-1 than COX-2. It seemed possible that ASA $15 \mathrm{cH}$ was interacting with COX-1 or COX2: thus a study with COX selective inhibitors was designed. Three groups of rats were separated as follows: (1) Shamoperated group + placebo; (2) Portal hypertension group + placebo; (3) Portal hypertension + ASA $15 \mathrm{cH}$. Each group was sub-divided into three further groups: oral placebo, SC 560 (COX-1 selective inhibitor) and NS 398 (COX-2 selective inhibitor). Both inhibitors were administered by gavage at a dose of $10 \mathrm{mg} / \mathrm{kg}$ b.w., suspended in CMC $0.5 \%$ at a final volume of $1 \mathrm{~mL} / \mathrm{kg}$ b.w. Only the solution of CMC was administered as oral placebo, corresponding to the selective COX inhibitors. ASA $15 \mathrm{cH}$ was effective in decreasing haemorrhage in the CMC group and in the group with COX-1 selective inhibition. In the laser-induced thrombosis method, ASA $15 \mathrm{cH}$ increased the number of emboli of the rats with portal hypertension and in the group with portal hypertension and COX-1 selective inhibition. Previous COX-2 inhibition blunted an effect of ASA $15 \mathrm{cH}$ on haemorrhage and thrombosis in portal hypertensive rats. Moreover, an inter- esting result was that portal hypertension induced an increased level of 6-keto-PGF $1 \alpha$, the stable metabolite of $\mathrm{PGI}_{2}$. This increased level, observed in portal hypertensive rats, decreased to a normal value in the group that received the treatment with ASA $15 \mathrm{cH}^{20}$

\section{Effects of Aspirin $15 \mathrm{cH}$ on Rats with Liver Cirrhosis}

The three previous studies were performed in a well-known experimental model of portal hypertension produced by portal vein ligation. That model is mainly haemodynamic and, although it mimics many of the changes observed in portal hypertension, it produces minimal changes in the liver architecture. A fourth study was designed to test if ASA $15 \mathrm{cH}$ was able to decrease haemorrhage in rats with severe chronic liver disease. Wistar male rats were divided into four groups. Two of them underwent bile duct ligation and section for 30 days. The other two (control) groups underwent a sham surgical procedure without ligation or section of the bile duct. The changes observed with this model of portal hypertension were similar to those observed with portal vein ligation: prolonged IHT, decreased number of emboli and decreased duration of embolisation (-Figs. 7 and 8). The differences were that the previously described studies had a more marked effect and rats with biliary cirrhosis were significantly unwell. However, the effects of ASA $15 \mathrm{cH}$ were the same in both experimental models. ${ }^{21}$

\section{Induced haemorrhagic time}

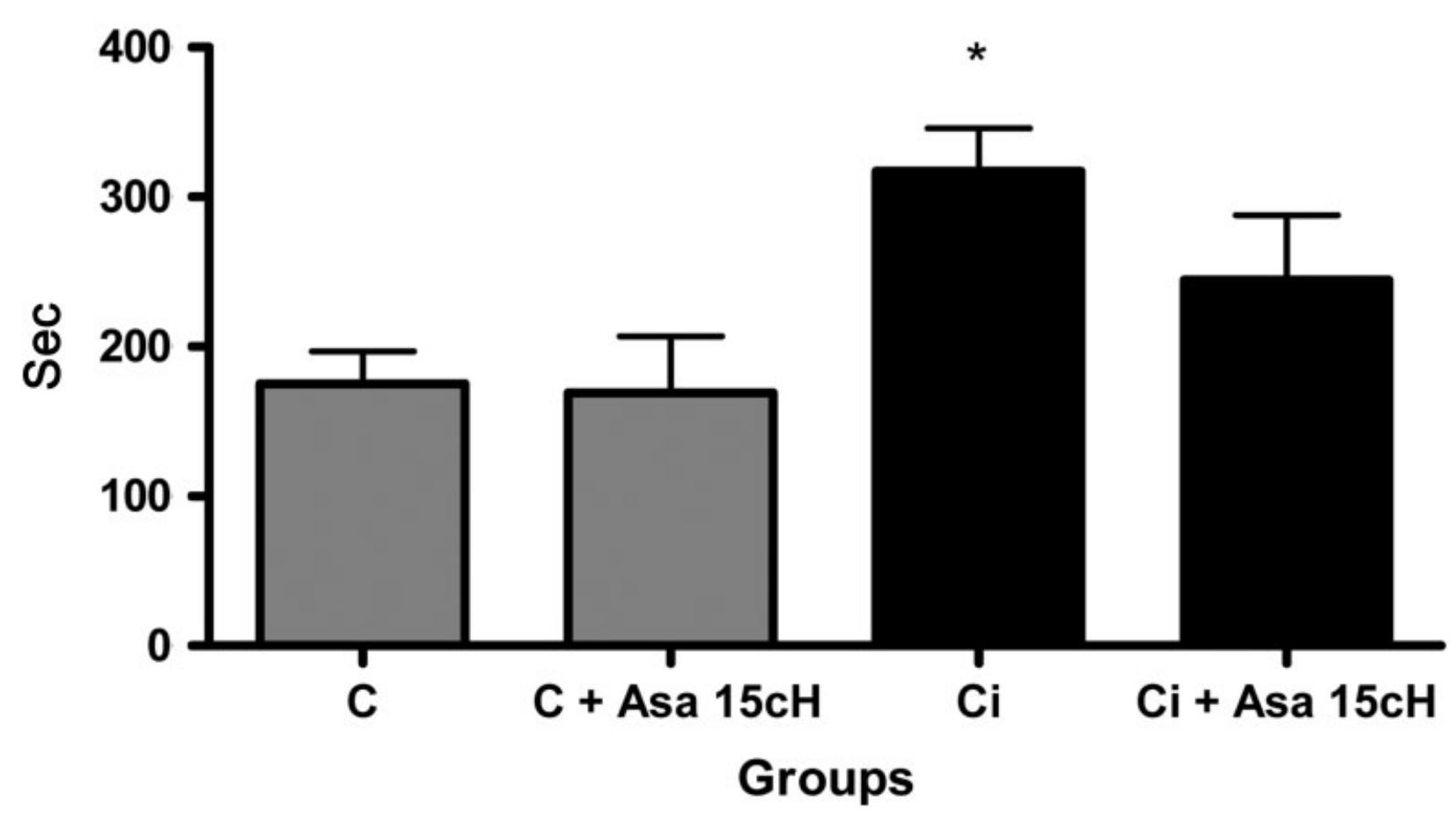

Fig. 7 Study of induced haemorrhagic time, expressed in seconds. Groups: sham control (C) + placebo; $\mathrm{C}+$ aspirin (Asa) $15 \mathrm{cH}$; cirrhosis (Ci) + placebo; $\mathrm{Ci}+$ Asa $15 \mathrm{cH}$. Analysis of variance with Bonferroni post-test: ${ }^{*} p<0.05$ versus control. Mean \pm standard error of mean. Reproduced with permission from Thrombosis. ${ }^{21}$ 


\section{Number of emboli}

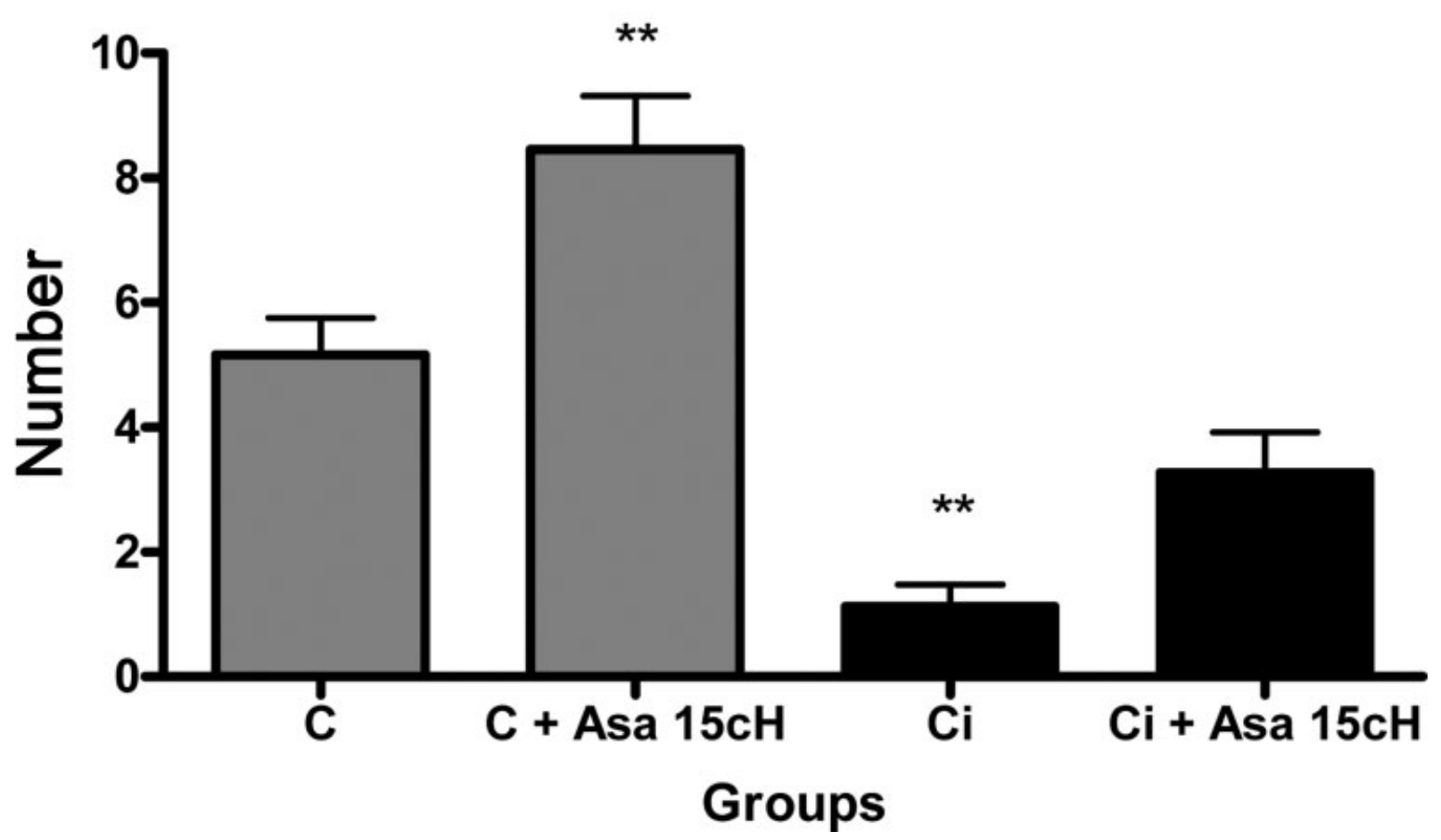

Fig. 8 Study of laser-induced thrombosis, expressed in numbers. Groups: sham control (C) + placebo; $\mathrm{C}+$ aspirin (Asa) $15 \mathrm{cH}$; cirrhosis (Ci) + placebo; $\mathrm{Ci}+$ Asa $15 \mathrm{cH}$. Analysis of variance with Bonferroni post-test. ${ }^{* *} p<0.001$ versus control. Mean \pm standard error of mean. Reproduced with permission from Thrombosis. ${ }^{21}$

\section{Discussion}

Aspirin produces an anti-thrombotic effect when used in low doses (e.g. $100 \mathrm{mg} /$ day). When prepared in the dilution $5 \mathrm{cH}$, this effect is clearly pro-thrombotic, as was determined in our early human studies and in the studies with platelet aggregation in-vitro. Subsequent studies done in rats determined that for the laser-induced thrombosis model the dilution with the most active pro-thrombotic effect was 15 $\mathrm{cH}$. This effect was produced 1 hour after subcutaneous injection. Similar effects were observed with $9 \mathrm{cH}$ and 30 $\mathrm{cH}$ dilutions.

When a rat is injected with the most active anti-thrombotic dose $(100 \mathrm{mg} / \mathrm{kg})$ in one dose and followed for many days, between days 8 and 10 there is a 'window' of increased thrombosis, which is an effect similar to that obtained 1 hour after the injection of ASA $15 \mathrm{cH}$. This observation is of great significance for human public health since there are many clinical reports that describe the same effect in patients who withdraw their aspirin treatment for the purpose of a surgical procedure or due to non-compliance. ${ }^{22}$ This effect is widely disregarded and risk appears to be increased for ischaemic stroke, ${ }^{23-25}$ cardiovascular problems, ${ }^{26-32}$ acute lower limb ischaemia ${ }^{33}$ and thrombosis of drug-eluting stents. ${ }^{34}$ The delay to the thrombotic event was between 7 and 30 days in many reports and most frequently 7 to 10 days. In the same model of basic research for thrombosis, ASA is probably the first drug that has been shown experimen- tally to possess: (1) an effect opposite to its primary effect several days after administration; (2) a secondary effect 1 hour after injection; (3) at the same time an extended doseresponse curve from $100 \mathrm{mg} / \mathrm{kg}$ to $30 \mathrm{cH}$.

Many studies warn about the clinical complications of drug withdrawal. These effects have been documented in many different fields of medicine. ${ }^{35}$ Common explanations for these effects include the complication of the untreated disease. In some cases, this so-called rebound effect is explained as the result of the biological adaptation to the drugs persisting once the drug is eliminated: for example, up-regulation or down-regulation of certain receptors. In the case of the described work, aspirin effects studied in their different aspects in our laboratory show a pro-thrombotic effect that is probably caused directly by the ultra-low dose. Further research will have to be done to find if the prothrombotic effect observed several days after one single high dose of ASA and the effect seen 1 hour after ASA $15 \mathrm{cH}$ are of exactly the same kind.

The mechanism of effect of ASA $15 \mathrm{cH}$ has been identified, with several different doses of COX-1 and COX-2 selective inhibitors in rats and with homozygous mice without COX-1 or without COX-2, giving similar results.

The pro-thrombotic effects of ASA proved to be beneficial: shortening IHT and normalising the altered thrombosis in rats with two different experimental models of portal hypertension, one of those models being of severe cirrhosis. These studies show that this pro-thrombotic effect does not only 
explain a side-effect that influences the use of ASA for the prevention of ischaemic problems but it may help in normalising the altered primary haemostasis in a severe pathology such as portal hypertension.

The importance of drug withdrawal effects is not restricted to ASA and nor to cardiovascular pharmacology. Such phenomena are more frequently considered in medicine as rebound effects. The relationship of rebound effect of many pharmacologically active drugs with homeopathy has been extensively analysed by Teixeira. ${ }^{36-38}$ In his articles, he makes a systematic search of such terms as 'rebound', 'paradoxical' and 'withdrawal', linked to the drugs to be analysed. However, when related to COX inhibitors, some of Teixeira's findings show differences from our experimental results. COX-1 and COX-2 inhibitors are likewise described as producing a secondary rebound effect of thrombosis after withdrawal, as found in observational evidence. In our results, COX-1-selective inhibition with SC-560 has a primary antithrombotic effect. COX-2-selective inhibition has a clear prothrombotic primary effect. Non-selective COX inhibition has an anti-thrombotic effect, this shown with indomethacin (a non-selective COX inhibitor with an effect mostly on COX-1) and with the addition of SC-560 and NS-398 (highly selective COX-1 and COX-2 inhibitors).

When analysing previously published raw data, ${ }^{15,19}$ the primary effect of COX inhibition is as follows: COX-1 selective inhibition decreases the number of emboli; COX-2 selective inhibition increases the number of emboli; indomethacin decreases the number of emboli; and SC-560 plus NS-398 together decrease the number of emboli (-Fig. 9). Thus, the pro-thrombotic result of COX-2 inhibition seems to be a primary more than a secondary effect. Unfortunately, the secondary effect of selective COX-2 inhibitors remains unstudied by our experimental model. As a consequence, we believe that observational evidence must lead basic experimental studies designed to disentangle the mechanisms underlying these complex effects.

One possible explanation for Teixeira's findings is that the COX-2 inhibitors used in clinical practice are less selective than NS-398. For example, rofecoxib inhibits COX-2 much
COX-1 selective inhibition

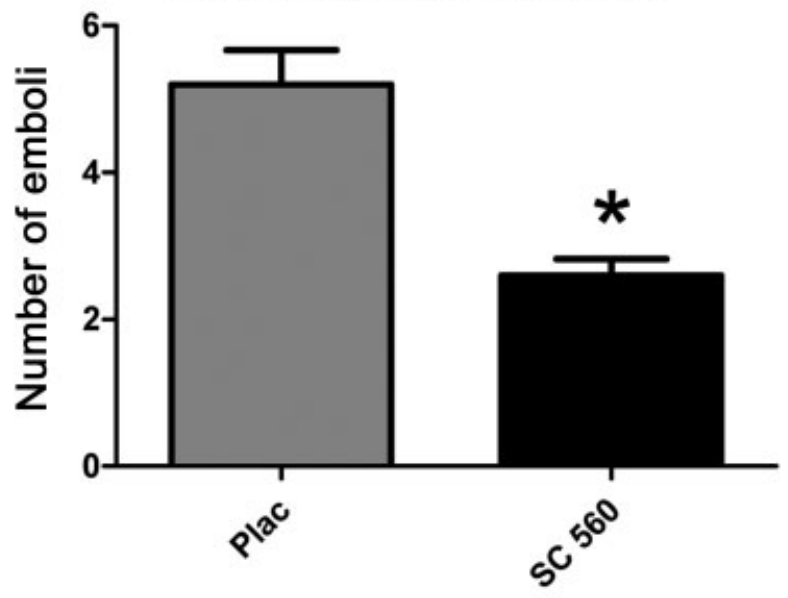

Indomethacin

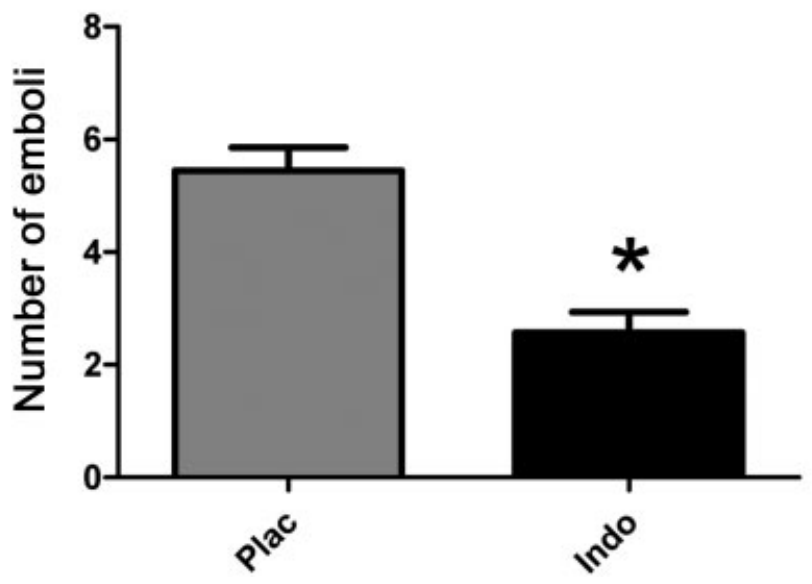

COX-2 selective inhibition

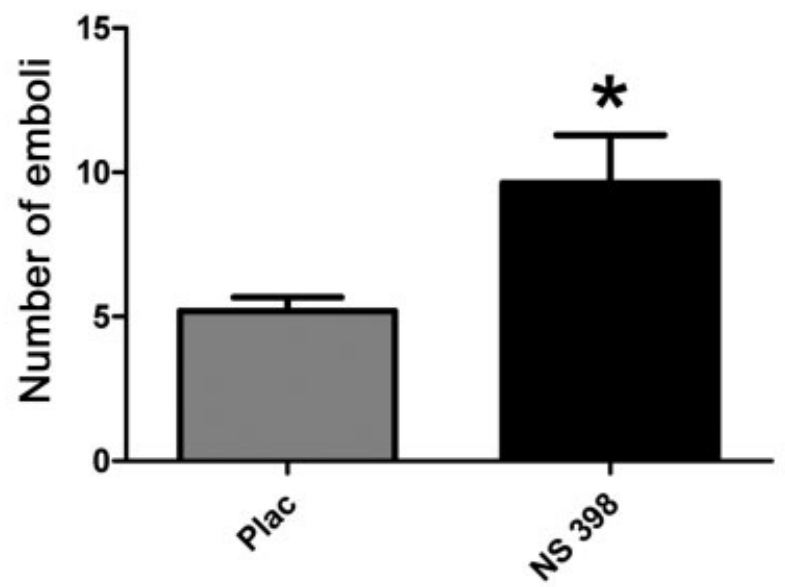

COX-1 plus COX-2 inhibition

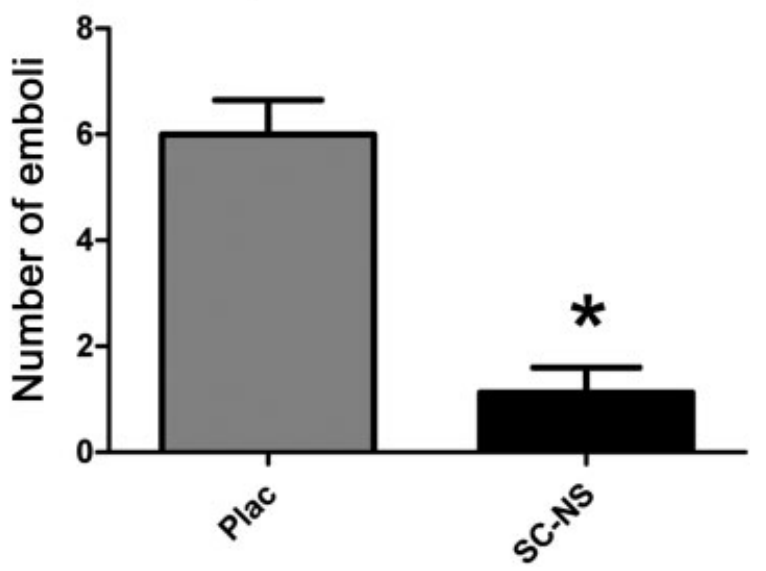

Fig. 9 Number of emboli. Effect of: cyclooxygenase-1 (COX-1) selective inhibition (SC $5602.5 \mathrm{mg} / \mathrm{kg}$ ), ${ }^{*} p<0.0001$; COX-2 selective inhibition (NS 398, $2.5 \mathrm{mg} / \mathrm{kg}$ ), ${ }^{*} p<0.01$; Indomethacin $2.5 \mathrm{mg} / \mathrm{kg},{ }^{*} p<0.0002$; SC 560 plus NS 398 (both at $10 \mathrm{mg} / \mathrm{kg}$ ), ${ }^{*} p<0.0001$. Unpaired $t$-tests, comparing test agent with placebo. Unpublished analysis of previously published data. ${ }^{15,19}$ 
less selectively than NS-398. In the case of ASA, the proposed mechanism is that the primary effect $(100 \mathrm{mg} / \mathrm{kg})$ is produced by COX-1 inhibition, decreasing $\mathrm{TXA}_{2}$ in the platelets. The secondary effect $(15 \mathrm{cH}, 1 \mathrm{~mL} / \mathrm{kg}$ ) seems to be produced in the endothelial cells, inhibiting the pathway of COX-2 and decreasing $\mathrm{PGI}_{2}$ production. ${ }^{20}$ It is interesting to note that our findings are linked to those described by Sainte-Laudy and Belon in their study on the effect of histamine dilution on $\mathrm{H}_{2}$ receptors, which showed a specificity of effect. ${ }^{39}$ Also worth noting is the similarity of the effect of ASA in different doses, in a specific way that differentiates between COX-1 and COX-2 - also one of the explanations of Calabrese in addressing a mechanistic explanation for hormesis, referring to different receptors' sensitivity to the same agonist, achieving opposite effects. ${ }^{40}$

Lastly, this subject is of considerable epidemiological importance, as stated in the recent article of Sundström et al, published in Circulation at the end of 2017. Analysing a cohort of more than 600,000 people in Sweden, they state that withdrawing long-term use of aspirin may increase the risk of a vascular event by $30 \% .{ }^{41}$

\section{Conclusions}

This body of evidence suggests that ASA $15 \mathrm{cH}$ has a strong pro-thrombotic effect, acting through the COX-2 pathway and having a possible therapeutic role in the bleeding complications of liver cirrhosis. This effect may have relevance in considering the problems observed after the withdrawal of the higher doses of aspirin used to decrease thrombo-embolic accidents in cardiology, and is a matter of public health importance.

\section{Highlights}

- ASA $15 \mathrm{cH}$ has a strong pro-thrombotic effect, opposite to that of low-dose aspirin used to prevent ischaemic accidents.

- Prior inhibition or the absence of COX-2 blunts the prothrombotic effect.

- The evidence examined in this article may contribute to clarifying the mechanism of effect of homeopathic dilutions.

- It may also help in understanding the complications observed after withdrawal of the larger doses of aspirin used to treat thrombo-embolic events.

\section{Conflict of Interest}

None declared.

\section{Acknowledgement}

The authors thank Mr. Dominique Duprat for his assistance in the production of this article.

\section{References}

1 Vane JR, Botting RM. The mechanism of action of aspirin. Thromb Res 2003;110:255-258

2 Doutremepuich C, de Seze O, Anne MC, Hariveau E, Quilichini R. Platelet aggregation on whole blood after administration of ultra low dosage acetylsalicylic acid in healthy volunteers. Thromb Res 1987;47:373-377

3 Doutremepuich C, Pailley D, Anne MC, de Sèze O, Paccalin J, Quilichini R. Template bleeding time after ingestion of ultra low dosages of acetyl salicylic acid in healthy subjects. Preliminary study. Thromb Res 1987;48:501-504

4 Doutremepuich C, Paillet D, De Seze O, Anne MC, Paccalin J, Quilichini R. Variation of bleeding time after administration of acetyl salicylic acid at different doses in the healthy volunteer [article in French]. Ann Pharm Fr 1988;46:35-39

5 Doutremepuich C, de Sèze O, Le Roy D, Lalanne MC, Anne MC. Aspirin at very ultra low dosage in healthy volunteers: effects on bleeding time, platelet aggregation and coagulation. Haemostasis 1990;20:99-105

6 Lalanne MC, Doutremepuich C, de Sèze O, Belon P. What is the effect of acetylsalicylic acid at ultra low dose on the interaction platelets/vessel wall? Thromb Res 1990;60:231-236

7 Lalanne MC, de Seze O, Doutremepuich C, Belon P. Could proteolytic enzyme modulate the interaction platelets/vessel wall in presence of ASA at ultra low doses? Thromb Res 1991; 63:419-426

8 Doutremepuich C, Aguejouf O, Belon P. Effects of ultra-low-dose aspirin on embolisation in a model of laser-induced thrombus formation. Semin Thromb Hemost 1996;22:67-70

9 Aguejouf O, Belougne-Malfatti E, Doutremepuich F, Belon P, Doutremepuich C. Thromboembolic complications several days after a single-dose administration of aspirin. Thromb Res 1998; 89:123-127

10 Belougne-Malfatti E, Aguejouf O, Doutremepuich F, Belon P, Doutremepuich C. Combination of two doses of acetyl salicylic acid: experimental study of arterial thrombosis. Thromb Res 1998;90:215-221

11 Aguejouf O, Malfatti E, Belon P, Doutremepuich C. Time related neutralization of two doses acetyl salicylic acid. Thromb Res 2000;100:317-323

12 Aguejouf O, Eizayaga F, Desplat V, Belon P, Doutremepuich C. Prothrombotic and hemorrhagic effects of aspirin. Clin Appl Thromb Hemost 2009;15:523-528

13 Doutremepuich CR, Aguejouf OM, Eizayaga FX, Desplat VL. Abstract 483: Reverse effect of aspirin: is the prothrombotic effect after aspirin discontinuation mediated by COX-2 blockade? Circulation 2007; 114:2-73

14 Doutremepuich C, Aguejouf O, Eizayaga FX, Desplat V. Reverse effect of aspirin: is the prothrombotic effect after aspirin discontinuation mediated by cyclooxygenase 2 inhibition? Pathophysiol Haemost Thromb 2007;36:40-44

15 Doutremepuich C, Aguejouf O, Desplat V, Eizayaga FX. Paradoxical thrombotic effects of aspirin: experimental study on 1000 animals. Cardiovasc Hematol Disord Drug Targets 2010;10:103-110

16 Doutremepuich C, Aguejouf O, Desplat V, Eizayaga F. Prothrombotic Effect After Aspirin Discontinuation is COX 2-dependent. Circulation 2009;120:S1032-S1033

17 Doutremepuich C, Aguejouf O, Desplat V, Eizayaga FX. Aspirin therapy: an attempt to explain the events of prothrombotic complications after treatment discontinuation. Thromb Haemost 2010;103:171-180

18 Eizayaga FX, Aguejouf O, Belon P, Doutremepuich C. Platelet aggregation in portal hypertension and its modification by ultra-low doses of aspirin. Pathophysiol Haemost Thromb 2005; 34:29-34

19 Eizayaga FX, Aguejouf O, Desplat V, Belon P, Doutremepuich C. Modifications produced by indomethacin and L-NAME in the effect of ultralow-dose aspirin on platelet activity in portal hypertension. Pathophysiol Haemost Thromb 2006;35:357-363

20 Eizayaga FX, Aguejouf O, Desplat V, Belon P, Doutremepuich C. Modifications produced by selective inhibitors of cyclooxygenase and ultra low dose aspirin on platelet activity in portal hypertension. World J Gastroenterol 2007;13:5065-5070 
21 Eizayaga FX, Aguejouf O, Desplat V, Doutremepuich C. Beneficial effect of ultra-low-dose aspirin in platelet activity alterations and haemorrhage observed in experimental portal hypertension. Thrombosis 2012;2012:430460

22 Doutremepuich C, Aguejouf O, Desplat V, Eizayaga FX. Aspirin discontinuation syndromes: clinical implications of basic research studies. Am J Cardiovasc Drugs 2013;13:377-384

23 Sibon I, Orgogozo JM. Antiplatelet drug discontinuation is a risk factor for ischemic stroke. Neurology 2004;62:1187-1189

24 Maulaz AB, Bezerra DC, Michel P, Bogousslavsky J. Effect of discontinuing aspirin therapy on the risk of brain ischemic stroke. Arch Neurol 2005;62:1217-1220

25 Armstrong MJ, Schneck MJ, Biller J. Discontinuation of perioperative antiplatelet and anticoagulant therapy in stroke patients. Neurol Clin 2006;24:607-630

26 Fischer LM, Schlienger RG, Matter CM, Jick H, Meier CR. Discontinuation of nonsteroidal anti-inflammatory drug therapy and risk of acute myocardial infarction. Arch Intern Med 2004; 164:2472-2476

27 Ferrari E, Benhamou M, Cerboni P, Marcel B. Coronary syndromes following aspirin withdrawal: a special risk for late stent thrombosis. J Am Coll Cardiol 2005;45:456-459

28 Burger W, Chemnitius JM, Kneissl GD, Rücker G. Low-dose aspirin for secondary cardiovascular prevention-cardiovascular risks after its perioperative withdrawal versus bleeding risks with its continuation-review and meta-analysis. J Intern Med 2005; 257:399-414

29 Collet JP, Montalescot G, Blanchet B, et al. Impact of prior use or recent withdrawal of oral antiplatelet agents on acute coronary syndromes. Circulation 2004;110:2361-2367

30 Ho PM, Spertus JA, Masoudi FA, et al. Impact of medication therapy discontinuation on mortality after myocardial infarction. Arch Intern Med 2006;166:1842-1847
31 Biondi-Zoccai GG, Lotrionte M, Agostoni P, et al. A systematic review and meta-analysis on the hazards of discontinuing or not adhering to aspirin among 50,279 patients at risk for coronary artery disease. Eur Heart J 2006;27:2667-2674

32 Collet JP, Himbet F, Steg PG. Myocardial infarction after aspirin cessation in stable coronary artery disease patients. Int J Cardiol 2000;76:257-258

33 Albaladejo P, Geeraerts T, Francis F, Castier Y, Lesèche G, Marty J. Aspirin withdrawal and acute lower limb ischemia. Anesth Analg 2004;99:440-443

34 Eisenberg MJ, Richard PR, Libersan D, Filion KB. Safety of shortterm discontinuation of antiplatelet therapy in patients with drug-eluting stents. Circulation 2009;119:1634-1642

35 Reidenberg MM. Drug discontinuation effects are part of the pharmacology of a drug. J Pharmacol Exp Ther 2011; 339:324-328

36 Teixeira MZ. Evidence of the principle of similitude in modern fatal iatrogenic events. Homeopathy 2006;95:229-236

37 Teixeira MZ. NSAIDs, myocardial infarction, rebound effect and similitude. Homeopathy 2007;96:67-68

38 Teixeira MZ. Rebound effect of modern drugs: serious adverse event unknown by health professionals. Rev Assoc Med Bras 2013;59:629-638

39 Sainte-Laudy J, Belon P. Inhibition of basophil activation by histamine: a sensitive and reproducible model for the study of the biological activity of high dilutions. Homeopathy 2009; 98:186-197

40 Calabrese EJ. Hormesis: why it is important to toxicology and toxicologists. Environ Toxicol Chem 2008;27:1451-1474

41 Sundström J, Hedberg J, Thuresson M, Aarskog P, Johannesen KM, Oldgren J. Low-dose aspirin discontinuation and risk of cardiovascular events: a Swedish nationwide, population-based cohort study. Circulation 2017;136:1183-1192 